\title{
Pengaruh Ekstrak Daun dan Ranting Aglaia odorata terhadap Parasitasi dan Enkapsulasi Eriborus argenteopilosus pada Inangnya, Crocidolomia binotalis
}

\author{
Udi Tarwotjo \\ Laboratorium Ekologi dan Biosistematik Jurusan Biologi FMIPA Undip
}

\begin{abstract}
Abstrak
Pengaruh ekstrak daun dan ranting A. odorata terhadap parasitasi dan enkapsulasi Eriborus argenteopilosus pada Crocidolomia. binotalis telah diteliti di laboratorium Tujuan penelitian ini adalah untuk mengetahui (1) toksisitas ekstrak daun dan ranting A. odorata terhadap C. binotalis, (2) mortalitas Eriborus argenteopilosus, (3) tingkat parasitasi dan enkapsulasi E. argenteopilosus Metode yang dipergunakan disusun berdasarkan RAL dengan 3 kali ulangan data dianalisis dengan sidik ragam (varians) dan perbedaan nilai tengah antar perlakuan diuji dengan DMRT. Toksisitas ekstrak daun dan ranting A. odorata terhadap larva $C$. binotalis instar satu menyebabkan kematian yang tinggi dengan meningkatnya konsentrasi dimana nilai $\mathrm{LC}_{50}$ sebesar 657,2470 mg/L, sedangkan $\mathrm{LC}_{90}$ sebesar 3353,6799 mg/L Tingkat parasitasi E. argenteopilosus terhadap C. binotalis pada konsentrasi 81,1485 mg/L $\left(\mathrm{LC}_{5}\right.$ ) ataupun $278,7482 \mathrm{mg} / \mathrm{L}\left(\mathrm{LC}_{25}\right)$ tidak berbeda nyata dengan kontrol. Sedangkan perlakuan ekstrak pada konsentrasi 278,7482 mg/L $\left(\mathrm{LC}_{25}\right)$ mampu menekan tingkat enkapsulasi.
\end{abstract}

Kata kunci: Eriborus argenteopilosus, Crocidolomia binotalis, Parasitasi. Encapsulasi

\begin{abstract}
Effects of extracted leaves and branches of Aglaia odorata (Melliaceae) on parasitation and encapsulation of Eriborus argenteopilosus on Crocidolomia binotalis were studied in laboratory. The obyektives of the study were to evaluate (1) the insectisidal toxicity of $A$. odorata extract against $C$. binotalis (2) effect of E. argenteopilosus female adult mortality and (3) level of extract on E. argenteopilosus parasitation and encapsulation. Experiment was laid out in completely randomized design with three replication. Date collected were subjected to an analysis variance followed by mean comparation based Duncan's Multiple Range Test The result showed that leaf and branch extract of A. odorata caused sufficienly high immortality of $C$. binotalis of first instar, and there were tendency of increasing mortality with increasing consentration, as indicated from the probit analisys which had an $\mathrm{LC}_{50}$ of $657,2470 \mathrm{mg} / \mathrm{Land}$ an $\mathrm{LC}_{90}$ of $3353,6799 \mathrm{mg} / \mathrm{L}$. The toxicity of these extracts were aplicated to E. argenteopilosus by topical contact application relatively not toxic. Rate of E. argenteopilosus parasitation when extract application was given at $81,1485 \mathrm{mg} / \mathrm{L}\left(\mathrm{LC}_{5}\right)$ or $278,7482 \mathrm{mg} / \mathrm{L}\left(\mathrm{LC}_{25}\right)$ was not significantly different from the control. With respect to encapsulation, extract concentration of $278,7482 \mathrm{mg} / \mathrm{L}\left(\mathrm{LC}_{25}\right)$ was able to depress encapsulation rate
\end{abstract}

Key word: Eriborus argenteopilosus, Crocidolomia binotalis, Parasitation. Encapsulation

\section{PENDAHULUAN}

Pemakaian insektisida kimia dalam usaha mengendalikan hama tanaman dan vektor penyakit mempunyai harga ekonomi yang relatif tinggi dan secara ekologis mempunyai dampak negatif yang memprihatinkan. Kenyataan ini menyebabkan perhatian para ilmuwan dan praktisi pengendali hama dan vektor penyakit beralih mencari alternatif lain dari insektisida kimiawi yang mempunyai dampak minimum terhadap komponen ekosistem.
Potensi tumbuhan sebagai insektisida botani sudah sejak lama digunakan untuk mengendalikan serangga hama. Senyawa kimia asal tumbuhan umumnya tidak menimbulkan gangguan yang fatal terhadap keseimbangan ekosistem dibandingkan dengan insektisida sintetik. Hal ini disebabkan karena insektisida botani lebih mudah terurai di alam dan relatif aman terhadap musuh alami hama dan organisme bukan sasaran (Priyono dan Triwidodo, 1993) 
Tumbuhan famili Meliaceae akhir-akhir ini banyak mendapat perhatian dari para ahli biologi dan ahli fitokimia, karena senyawa kimia yang dikandungnya bersifat antifeedant, repelen, dan bersifat insektisidal.(Chiu, 1985). Salah satu anggota Meliaceae yang berpotensi sebagai insektisida botani adalah Aglaia odorata.. Ishibasi et al. (1983) dan Janprasert et al. (1993) melaporkan bahwa isolasi dan identifikasi daun dan ranting $A$. odorata menghasilkan senyawa benzofuran yaitu rokaglamida yang mempunyai aktivitas insektisida dan IGR (insecticide growth regulator) terhadap Peridroma saucia dan Spodoptera litura(Lepidoptera: Noctuidae)

Hama utama perusak daun kubis adalah Plutella xylostella $\mathrm{L}$ dan Crocidolomia binotalis Zell (Lepidoptera:Pyrallidae) yang pada musim kemarau dapat menyebabkan kerusakkan total. Di Negara-negara maju, kehilangan hasil akibat gangguan hama dan penyakit tanaman kubis berkisar antara $25-50 \%$, dan di Negara-negara berkembang diperkirakan dapat mencapai 80 persen (Robert, 1978)

Penggunaan insektisida untuk mengendalikan $C$. binotalis mempunyai dampak negatif, yaitu timbulnya resistensi hama tanaman dan vektor penyakit, timbulnya resurgensi hama, pencemaran lingkungan yang berbahaya bagi jiwa manusia dan biota lain, serta semakin besarnya biaya pengendalian karena dosis serta harga yang semakin meningkat. Disamping itu juga terbunuhnya parasitoid Diadegma semiclaususm yang merupakan musuh alami P.xylostella, karena C. binotalis dan $P$. xylostella terdapat dalam satu habitat daun kubis. Oleh karena itu penggunaan insektisida botani sebagai solusi alternatif dalam mengatasi permasalah hama yang sekaligus permasalahan lingkungan

Pengaruh bahan insektisida botani ( $A$. odorata) terhadap parasitoid belum pernah diteliti. Insektisida yang berasal dari tumbuhan tidak dapat dijamin aman terhadap musuh alaaminya. Karena itu pengaruh ekstrak daun dan ranting $A$. odorata perlu diuji secara khusus terhadap sistem interaksi inang-parasitoid tertentu. Salah satu sistem interaksi inang-parasitoid yang menarik untuk diteliti, adalah interaksi antara $C$. binotalis dan parasitoid Eriborus argenteopilosus (Cameron) (Hymenoptera : Ichneumonidae). Tingkat parasitasi E. argenteopilosus di lapang hanya 2,23 persen ( Othman, 1982), tetapi parasitasi oleh parasitoid ini tidak efektif akibat terjadinya enkapsulasi terhadap telur dan larva parasitoid tersebut. Tingkat enkapsulasi telur dalam skala laboratorium berkisar antara 2,0-7,0 persen (Hadi, 1985).

\section{BAHAN DAN METODE}

Penelitian ini dilaksanakan di Laboratorium Ekologi dan Biosistematika Jurusan Biologi fak. MIPA Undip. Waktu penelitian 5 bulan mulai April-Agustus 2009

\section{Tahap Penelitian}

\section{Pengujian Toksisitas Ekstrak Daun dan Ranting A. odorata terhadap Larva C. binotalis Instar Satu}

Daun yang telah diberi perlakuan ekstrak dan kontrol (daun hanya dicelupkan ke dalam larutan metanol tanpa perlakuan ekstrak) dimasukkan kedalam tujuh botol gelas (tinggi 20 $\mathrm{cm}$ dan diameter $10 \mathrm{~cm}$ ) sesuai konsentrasi yang dikehendaki, dan pada setiap botol dimasukkan 10 ekor larva $C$. binotalis instar satu yang sebelumnya telah dilaporkan selama 24 jam. Perlakuan ekstrak terhadap larva hanya dilakukan sekali saja yaitu pada hari pertama, sedangkan pada hari kedua dan selanjutnya hinggá saat larva menjelang kepompong, serangga uji hanya diberi pakan daun kubis segar tanpa perlakuan ekstrak.

Jumlah larva yang mati dicatat setiap hari dan seterusnya sampai tidak ada larva yang mati. Jumlah larva yang mati dihitung pada setiap konsentrasi, kemudian dianalisis dengan Probit Analisis (Finney, 1971) untuk mengetahui LC $_{50}$ dan $\mathrm{LC}_{90}$. Parameter yang diamati adalah jumlah kematian serangga uji

\section{Pembiakan Masal Parasitoid E. argentopilosus}

Parasitoid diperoleh dengan cara mengayunkan jaring serangga pada area perkebunan kubis, kemudian dipelihara ditempat pembiakan parasitoid yang di dalamnya diberi kapas yang dicelupkan pada cairan gula $10 \%$, juga diberikan umpan larva sebanyak 10 ekor larva instar pertama dan kedua. Parasitoid yang muncul 
dibiakkan lebih lanjut sampai jumlah parasitoid mencukupi untuk pengujian toksisitas ekstrak

\section{Cara Ekstraksi Daun dan Ranting A. odorata dan Cara Membuat Larutan Uji}

Daun dan ranting A. odorta yang diperoleh dibersihkan dan dikering anginkan serta digerus dengan menggunakan mortil ke dalam mangkok porselin sampai halus sebanyak 100 g. Hasil gerusan ditampung kedalam satu mangkok porselin, dan dimasukkan ke dalam erlenmeyer dan ditambahkan $400 \mathrm{ml}$ metanol. Campuran tersebut diaduk dengan menggunakan corong Buchner yang dialasi kertas saring Whatman no 1 . Cairan ekstrak hasil saringan diuapkan pelarutnya dengan menggunakan rotary evaporator pada suhu $45^{\circ}-50^{\circ}$ dan tekanan $15 \mathrm{~mm} \mathrm{Hg}$ sampai volume minimum (F:1). Kemudian filtrat dimasukkan ke dalam corong funnel dengan campuran metanolkloroform-air (1:3:4) dan 0,7\% $\mathrm{NaCl}$, dibiarkan 24 jam sampai terjadi pemisahan menjadi lapisan air dan metanol kloroform (F:2). Selanjutnya metanol kloroform diuapkan kembali dengan menggunakan rotary evaporator. Labu penguap ditimbang lebih dahulu sebelum ekstrak dimasukkan, kemudian labu dan ekstrak dimasukkan ke dalam labu penguap. Setelah penguapan selesai, labu dan esktrak ditimbang kembali sehingga berat ekstrak dapat diketahui. Ekstrak disimpan dalam lemari $\left(\mathrm{t}^{\mathrm{o}}\right.$ $<4^{\circ} \mathrm{C}$ ) sampai menunggu saat digunakan untuk uji hayati.

Cara membuat larutan uji dengan metode residu pada daun. Serial konsentrasi yang digunakan adalah 50, 75, 100, 125, 150, dan 175 $\mathrm{mg} / \mathrm{L}$. Ekstrak daun dan ranting A. odorta dilarutkan dalam $400 \mathrm{~mL}$ metanol untuk dibuat larutan induk dengan konsentrasi $1000 \mathrm{mg} / \mathrm{L}$. Kemudian dari larutan induk diambil $0,5 \mathrm{~mL}$ yang dilarutkan dengan metanol sampai $10 \mathrm{~mL}$ untuk membuat larutan uji $50 \mathrm{mg} / \mathrm{L}$, demikian untuk konsentrasi yang lain. Larutan induk disimpan dalam lemari es $\left(<4^{\circ} \mathrm{C}\right)$ selama tidak digunakan.

\section{Pengujian Ekstrak Daun dan Ranting $A$. odorta terhadap Parasitasi dan Enkapsulasi}

Daun kubis yang mengandung residu ekstrak diujikan terhadap larva instar satu $C$. binotalis, dan diinfestasikan dengan imago E. argenteopilosus yang sudah kawin. Konsentrasi yang diujikan adalah konsentrasi yang setingkat dengan $\mathrm{LC}_{5}$ dan $\mathrm{LC}_{25}$. Daun perlakuan dan kontrol ditempatkan dalam botol gelas. Setiap perlakuan diulang 3 kali.

Pengamatan dilakukan pada hari ke dua setelah perlakuan dan larva diberi pakan daun kubis segar tanpa perlakuan ekstrak, demikan juga pada hari-hari berikutnya. Sedangkan pada parasitoid diberi pakan larutan gula $10 \%$ pada bola-bola kapas. Ada tidaknya telur parasitoid di dalam tubuh larva $C$. binotalis dapat diamati dengan keluarnya parasitoid, dan proses enkapsulasi pada telur ataupun larva dilakukan pembedahan larva di bawah mikroskop binokuler. Pembedahan dilakukan terhadap larva instar empat setelah dipastikan tidak ada parasitoid yang keluar dari larva tersebut.

Parameter yang diamati adalah menghitung jumlah telur perasitoid yang diletakkan dan yang terenkapsulasi. Parameter parasitasi dapat dihitung dengan menggunakan rumus:

$$
\mathrm{P}(\%)=\frac{\sum \operatorname{lp}}{\sum \ln } \mathrm{x} 100 \%
$$

Keterangan :

$\mathrm{P}=$ parasitasi

lp $=$ jumlah larva $C$. binotalis yang terparasit

$\ln =$ jumlah total larva $C$. binotalis yang diujikan

Sedangkan persentase telur dan larva yang terenkapsulasi dapat dihitung dengan menggunakan rumus:

$$
\mathrm{E}(\%)=\frac{\sum \text { te }}{\sum \text { tn }}
$$

Keterangan :

$\mathrm{E}=$ enkapsulasi

$\mathrm{lp}=$ jumlah telur E. argenteopilosus yang terenkapsulasi

$\ln =$ jumlah total E. argenteopilosus yang diletakan

Penelitian ini dilakukan dengan metode Rancangan Acak Lengkap (RAL). Data dianalisis dengan sidik ragam dan perbandingan nilai tengah antar perlakuan diuji dengan DMRT (Stell and Torrie, 1980) 
HASIL DAN PEMBAHASAN

1. Pengujian Toksisitas Ekstrak Daun dan Ranting $A$. odorata terhadap Larva $C$. binotalis Instar Satu

Konsentrasi yang digunakan selama pengujian toksisitas ekstrak daun dan ranting $A$. odorata terhadap tingkat mortalitas larva $C$. binotalis, adalah konsentrasi yang didasarkan dari hasil uji pendahuluan. Konsentrasi yang digunakan selama pengujian toksisitas ekstrak ini diawali dari 250, 500, 750, 1000, 1250, dan $1500 \mathrm{mg} / \mathrm{L}$ Hasil pengujian ditunjukkan pada tabel I

Tabel 1: Tingkat kematian larva $C$. binotalis instar satu.pada berbagai konsentrasi ekstrak daun dan ranting $A$. odorata pada hari ke 10 setelah perlakuan

\begin{tabular}{|c|c|c|c|c|c|}
\hline \multirow[t]{3}{*}{$\begin{array}{c}\text { Perlakuan } \\
(\mathrm{mg} / \mathrm{L})\end{array}$} & \multicolumn{5}{|c|}{$\begin{array}{l}\text { Tingkat kematian larva } C \text {. binotalis pada } \\
\text { berbagai konsentrasi }\end{array}$} \\
\hline & \multicolumn{3}{|c|}{ Jumlah Ulangan } & \multirow[t]{2}{*}{ Total } & \multirow[t]{2}{*}{ Rerata } \\
\hline & I & II & III & & \\
\hline 250 & 40 & 60 & 20 & 120 & 40 \\
\hline 500 & 90 & 40 & 30 & 160 & 50,33 \\
\hline 750 & 40 & 60 & 20 & 120 & 40 \\
\hline 1000 & 40 & 80 & 50 & 170 & 50,66 \\
\hline 1250 & 70 & 80 & 70 & 220 & 70,33 \\
\hline 1500 & 90 & 80 & 80 & 250 & 80,33 \\
\hline Kontrol & 0 & 0 & 0 & 0 & 0 \\
\hline
\end{tabular}

Hasil menunjukkan adanya kecenderungan, bahwa pada konsentrasi ekstrak yang semakin tinggi menyebabkan tingkat kematian yang semakin meningkat. Semakin tinggi konsentrasi ekstrak, maka semakin tinggi pula daya toksisitasnya terhadap larva instar satu $C$. binotalis Hasil analisis probit taksisitas ekstrak daun dan ranting $A$. odorata terhadap larva $C$. binotalis instar satu menunjukkan bahwa nilai $\mathrm{LC}_{50}$ ekstrak tersebut sebesar $657,2470 \mathrm{mg} / \mathrm{L}$, sedangkan $\mathrm{LC}_{90}$ sebesar 3353,6799 mg/L

2. Pengaruh Ekstrak Daun dan Ranting $A$. odorata terhadap Mortalitas Parasitoid $E$. argenteopilosus imago betina

Konsentrasi ekstrak yang digunakan dalam pengujian ini adalah 3353,6799 $\mathrm{mg} / \mathrm{L}\left(\mathrm{LC}_{90}\right)$. Pengaruh ekstrak terhadap tingkat mortalitas parasitoid E. argenteopilosus imago betina ditunjukkan pada tabel 2:
Tabel 2: Tingkat kematian E. argenteopilosus imago betina setelah perlakuan ekstrak daun dan ranting A. odorata dengan aplikasi topikal kontak

\begin{tabular}{|c|c|c|c|c|}
\hline \multirow{3}{*}{$\begin{array}{c}\text { Perlakuan } \\
\text { ekstrak daun } \\
\text { dan ranting } \\
\text { A, odorata }\end{array}$} & \multicolumn{4}{|c|}{$\begin{array}{c}\text { Tingkat kematian parasitoid } E \text {. } \\
\text { argenteopilosus imago betina } \\
\text { pada hari ketiga setelah perlakuan }(\%)\end{array}$} \\
\hline & \multicolumn{3}{|c|}{ Pengamatan pada hari ke: } & \multirow{2}{*}{$\begin{array}{l}\text { rerata } \\
\text { Kemati } \\
\text { an }(\%)\end{array}$} \\
\hline & 1 & 2 & 3 & \\
\hline $\begin{array}{c}657,2470 \\
\mathrm{mg} / \mathrm{L}\left(\mathrm{LC}_{50}\right)\end{array}$ & 0 & 20 & 0 & 6,67 \\
\hline $\begin{array}{c}3353,6799 \\
\mathrm{mg} / \mathrm{L} \\
\left(\mathrm{LC}_{90}\right)\end{array}$ & 0 & 0 & 20 & 6,67 \\
\hline Kontrol & 0 & 0 & 20 & 6,67 \\
\hline
\end{tabular}

Keterangan: 0: tidak ada parasitoid yang mati; $\mathrm{N}=5$

Hasil menunjukkan bahwa perlakuan dengan konsentrasi $657,2470 \mathrm{mg} / \mathrm{L} \quad\left(\mathrm{LC}_{50}\right)$, kematian terjadi pada hari ke-2, rerata kematian sebesar 6,67 $\%$. Presentase kematian tidak meningkat meskipun konsentrasi ditinggikan sampai 3353,6799 m/L $\left(\mathrm{LC}_{90}\right)$, dan hasil tidak berbeda nyata dengan kontrol. Hal ini menunjukkan, bahwa pengaruh ekstrak daun dan ranting A. odorata relatif tidak beracun terhadap parasitoid E. argenteopilosus imago betina. Pada umumnya senyawa metabolit sekunder pada tanaman akan bersifat toksis apabila diaplikasikan secara oral dibandingkan aplikasinya melalui topikal kontak epidermis (Matsumura, 1985)

\section{Pengaruh Ekstrak Daun dan Ranting $A$. odorata terhadap Tingkat Parasitasi dan Enkapsulasi E. argenteopilosus}

Parasitoid yang digunakan sebagai serangga uji adalah E. argenteopilosus dewasa betina yang telah berkopulasi. Sedangkan konsentrasi ekstrak daun dan ranting $A$. odorata yang diujikan terhadap tingkat parasitasi dan enkapsulasi $E$. argenteopilosus adalah $\mathrm{LC}_{5}$ dan $\mathrm{LC}_{25}$ hasil analisis probit uji toksisitas ekstrak terhadap mortalitas $C$. binotalis instar satu. Perlakuan parasitasi terhadap larva instar satu $C$. binotalis, setelah larva diberi pakan dengan konsentrasi ekstrak 81,1485 mg/L yang setara dengan $\mathrm{LC}_{5}$ dan konsentrasi ekstrak $278,7482 \mathrm{mg} / \mathrm{L}$ yang setara dengan $\mathrm{LC}_{25}$. Hasil uji ekstrak terhadap parasitasi dan enkapsulasi ditunjukkan pada tabel 3 . 
Tabel 3: Tingkat parasitasi E. argenteopilosus dewasa betina dan enkapsulasi larva $C$. binotalis terhadap telur dan larva E. argenteopilosus

\begin{tabular}{ccccc}
\hline Konsentrasi ekstrak & \multicolumn{3}{c}{ Proses yang berlangsung (\%) } \\
$(\mathrm{mg} / \mathrm{L})$ & Parasi & Enkaps & \multicolumn{2}{c}{ Enkapsulasi } \\
& tasi & ulasi & telur & larva \\
$81,1485\left(\mathrm{LC}_{5}\right)$ & $4,44 \mathrm{a}$ & $60 \mathrm{ab}$ & $25 \mathrm{a}$ & $50 \mathrm{a}$ \\
$278,7482\left(\mathrm{LC}_{25}\right)$ & $5,55 \mathrm{a}$ & $40 \mathrm{a}$ & $20 \mathrm{a}$ & $20 \mathrm{a}$ \\
Kontrol & $5,55 \mathrm{a}$ & $80 \mathrm{~b}$ & $40 \mathrm{a}$ & $40 \mathrm{a}$
\end{tabular}

Data dengan huruf yang sama pada kolom yang sama menunjukkan tidak berbeda nyata (Uji DMRT pada $\alpha$ $0,05)$

Hasil menunjukkan, bahwa tingkat parasitasi E. argenteopilosus terhadap inangnya, $C$. binotalis pada perlakuan konsentrasi ekstrak 81,1485 $\mathrm{mg} / \mathrm{L}\left(\mathrm{LC}_{5}\right)$ ataupun $278,7482 \mathrm{mg} / \mathrm{L}\left(\mathrm{LC}_{25}\right)$ tidak berbeda nyata dengan kontrol. Sedangkan perlakuan ekstrak pada konsentrasi 278,7482 $\left(\mathrm{LC}_{25}\right)$ mampu menekan tingkat enkapsulasi. Rendahnya tingkat enkapsulasi baik pada stadium telur ataupun larva pada perlakuan 278,7482 $\left(\mathrm{LC}_{25}\right)$ disebabkan karena ekstrak mempunyai sifat racun yang menghambat perkembangan melalui ketidak keseimbangan hormon, terutama yang berkaitan dengan proses deferensiasi dan perkembangan sel-sel darah. Chapman (1982) mengatakan, bahwa sel-sel darah berperan dalam proses enkapsulasi dan fagositosis terhadap bendabenda asing yang masuk ke dalam tubuh. Disamping itu, rendahnya tingkat enkapsulasi disebabkan karena larva parasitoid yang ada di dalam tubuh inangnya aktif bergerak untuk melawan enkapsulasi. Cara tersebut merupakan salah satu strategi perlawanan untuk menghindari proses enkapsulasi

\section{KESIMPULAN}

Tingkat parasitasi E. argenteopilosus terhadap inangnya, $C$. binotalis dengan perlakuan ekstrak daun dan ranting $A$. odorata pada konsentrasi $81,1485 \mathrm{mg} / \mathrm{L}\left(\mathrm{LC}_{5}\right)$ ataupun 278,7482 $\mathrm{mg} / \mathrm{L}\left(\mathrm{LC}_{25}\right)$ tidak berbeda nyata dengan kontrol. Sedangkan perlakuan ekstrak pada konsentrasi
$278,7482 \quad\left(\mathrm{LC}_{25}\right)$ mampu menekan tingkat enkapsulasi.

\section{DAFTAR PUSTAKA}

Chiu, S.F., 1985. Recent researh finding on Meliaceae and other promising botanical insecticides in China 92: 310-319

Chapmann, R,F., 1982. The Insects. Strukture and Function. $3^{\text {rd }}$ ed. Harvard University Press. Cambridge Massachuchusetts

Finney, D.J.. 1971 Probit Analysis, 3 rd ed. Cambridge Univ. Press, Cambridge, England

Hadi, S., 1985 Biologi dan Perilaku Inareolata sp. (Hymenoptera: Ichneumonidae). Parasitoid larva padsa hama kubis Crocidolomia binotalis Zell (Lepidoptera:Pyrallida) Tesis S2 Fakultas Pascasarjana Institut Pertania Bogor. 50 hal.

Ishibashi, F., C. Satasook, M.B. Ishman, and G.H. Neil Towers, 1983. Insecticidal $1 \mathrm{H}$ Cyclopenta tetra hidro (b) benzofuran from Aglaia odorata, Phytochemistry, 32, pp. 307

Janprasert, J., C. Satasook, P. Sukamalanand, D.E. Champagne, M.B. Ishman, P. Wiriacitra and G.H.N. Towers, 1993.. Insecticidal 1 HCyclopenta tetra hidro (b) benzofuran from Aglaia odorata, Phytochemistry, 32: pp.. 307

Matsumura,. 1985 Toxicology of Insecticide, $3^{\text {rd }}$ ed Plenum Press, New York. p. 218-312

Othman, N., 1982. Biology of Crocidolomia binotalis Zell (Lepidoptera: Pyrallidae) and its parasites from Cipanas area (West Java), Biotrop, Bogor, Indonesia, 52 p.

Prijono, D., H. Triwidodo, 1993. Pemanfaatan Insektisida Nabati di Tingkat Petani.Hal 7685. Prosiding Seminar hasil Penelitian dalam rangka Pemanfaatan Insektisida Nabati. Bogor, 1-2 Desember 1993

Steel., R.G.D., and J.H. Torrie, 1980. Principle and Prosedures of Statistics: Biometrical and Approach, $2^{\text {nd }}$ ed. McGraw-Hill, NewYork 